\title{
Six pioneers artistically celebrated by the Andalusian Society of Nuclear Medicine
}

\author{
Poul F. Høilund-Carlsen ${ }^{1,2}$ (D) Salomé Sanz-Viedma ${ }^{3}$ \\ Published online: 10 July 2020 \\ (C) Springer-Verlag GmbH Germany, part of Springer Nature 2020
}

The Andalusian Society of Nuclear Medicine decided to announce its 27th annual conference held in Málaga 2021 March 2020 with a poster (Fig. 1) holding an artistic drawing of the town's ancient Roman theatre built in the age of Augustus and in use until the third century when it became a source of stone for the Arabic conquerors, who erected buildings of their own. What remains of the theatre was rediscovered in 1951 near the Casa de la Cultura (House of Culture) and is still being excavated with significance for European culture and for the city of Málaga in particular.

Unfortunately, like many other large gatherings in Europe, the congress was canceled at short notice to help reduce the spread of the Covid-19 virus. What remains of the annual meeting is its artistic poster depicting below the magnificent Roman amphitheater the heads of six of some of the most significant pioneers in our field (from left to right): Marie Curie (1867-1934), George Hevesy (18851966), Ernest Lawrence (1901-1958), Abass Alavi (1938-), Michael Phelps (1939-), and Peter Ell (1944-). They contributed to the basis and/or with such significant contributions to what we nowadays term nuclear medicine and molecular imaging that they will never be forgotten,

This article is part of the Topical Collection on Editorial

Poul F. Høilund-Carlsen

pfhc@rsyd.dk

1 Department of Nuclear Medicine, Odense University Hospital, 5000 Odense C, Denmark

2 Research Unit of Clinical Physiology and Nuclear Medicine, Department of Clinical Research, University of Southern Denmark, Odense, Denmark

3 Department of Nuclear Medicine, Hospital Universitario Virgen de la Victoria de Málaga, Málaga, Spain regardless of new coronavirus infections or other serious challenges to our civilization.

To sum up their merits in a few words, in addition to the 4 Nobel Prizes awarded to the three diseased pioneers (two to Curie and one to Hevesy and Lawrence), it must be that Madame Curie, as she is also called, was the first who actually understood and described the nature of radioactivity, a word that she even coined, while Hevesy invented and applied the tracer principle using radioactive isotopes to study biological processes, and Lawrence invented and produced the first cyclotron without which there would have been no PET or clinical molecular imaging.

Among the still ongoing colleagues on the list, Alavi is the co-founder and active promoter of the allimportant tracer FDG, which has provided new insights into multiple serious diseases and helped countless people to a more accurate diagnosis; Phelps played a major role in designing and building successful PET I instruments and in promoting its role as a powerful technology in medicine, while, finally, Ell was the exquisite international advocate of nuclear medicine and molecular imaging, founder of the European Association of Nuclear Medicine (EANM) and for a number of years successful Editor-in-Chief of the European Journal of Nuclear Medicine.

Looking ahead, it may be appropriate to recall the words of Peter Ell, when he was bestowed the Hevesy award in 2008: "It is imperative to recruit the brightest and most able to our field, in order to foster innovation and enterprise. It is essential to transmit a vision and develop an environment, where the disciplines of physics, radiochemistry and molecular biology cross fertilize and contribute to the betterment of patient's lives. The burden of costly over regulation poses a major challenge, since it can stifle innovation or delay its translation into clinical practice." Ten years later, referring to the everincreasing importance of artificial intelligence and wearable 


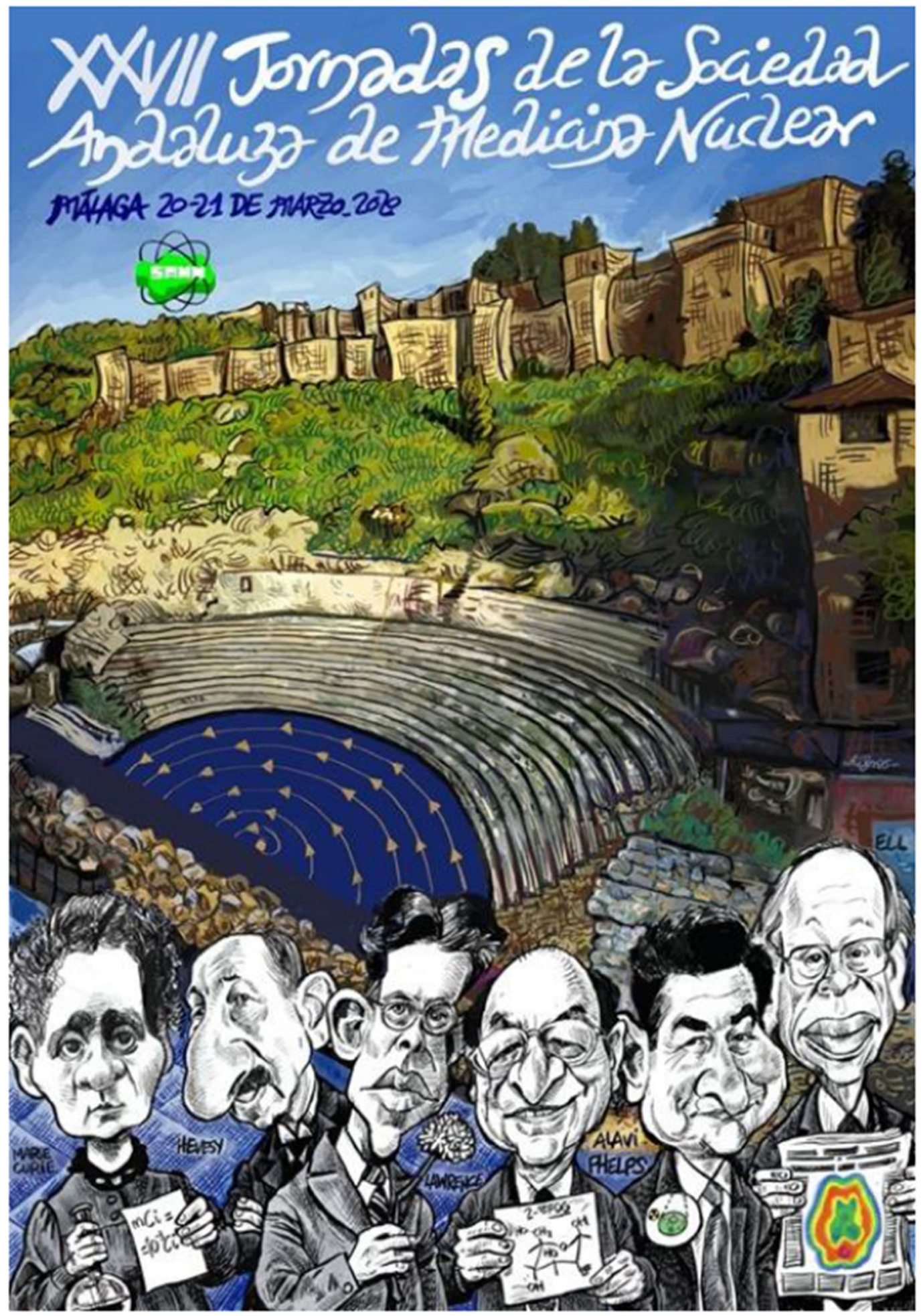

Fig. 1 Poster advertising the 27th annual congress of the Andalusian Society of Nuclear Medicine. The poster is reproduced by permission of the artist and Servicio de Medicina Nuclear, Hospital Clinico Virgen de la Victoria, Málaga, Spain

electronic devices, he pointed to the fact that openness and willingness to interact with these new opportunities is a necessity for us to maintain the importance and influence of our imaging expertise [1]. 
Acknowledgments Colleagues at the Department of Nuclear Medicine, Hospital Universitario Virgen de la Victoria de Málaga, Spain, and the persons and institution who gave their permission to reproduce the included illustration are thanked for their kind help.

\section{Compliance with ethical standards}

Conflict of interest The authors declare that they have no conflict of interest.

Ethical approval This article does not contain any studies with human participants or animals performed by the author.

\section{References}

1. Ell PJ. A fresh breeze sweeps through nuclear medicine 2018. Clin Transl Imaging. 2018;6:415-6.

Publisher's note Springer Nature remains neutral with regard to jurisdictional claims in published maps and institutional affiliations. 